\title{
BIMBINGAN BELAJAR UNTUK MENINGKATKAN MOTIVASI BERPRESTASI ATLET BOLA VOLI O2SN KABUPATEN MAJALENGKA
}

\author{
Yucky Putri Erdiyanti, Bayu Dwi Febriyanto \\ Universitas Majalengka \\ Yuckyerdiyanti@gmail.com, Bayudwifebriyanto@gmail.com
}

\begin{abstract}
The research is motivated by the lack of achievement motivation in the academic field of volleyball athletes in Majalengka Regency. One effort to improve achievement motivation in the academic field is to use tutoring. One vehicle to improve the quality of human resources can be done through the field of sports. Volleyball game is one sport that is very popular in the community. The purpose of doing volleyball is very diverse, from just for entertainment or recreation, health sports, educational sports to those that aim to achieve maximum performance. This study aims to (1) Know the volleyball athlete's learning motivation profile before and after being given tutoring, (2) Generate a tutoring program to improve volleyball athlete's learning motivation, (3) Obtain empirical data about the effectiveness of the tutoring program to increase motivation studying athlete. To produce effective tutoring pursued by preliminary studies, instrument development, instrument feasibility testing, development of tutoring, feasibility study guidance and tutoring trials this research approach uses a quantitative approach with a quasi-experimental method and the design is the pretest-posttest control group design against O2SN volleyball athletes in Majalengka district. Data collection uses a measuring instrument in the form of achievement motivation instruments. The results showed empirically, the treatment in the form of proven tutoring was not effective in increasing volleyball athlete achievement motivation. It is expected to know the level of achievement motivation of volleyball athletes at the beginning of the lecture, so that they can plan the programs that must be performed Achievement motivation.
\end{abstract}

Keywords: Tutoring; Athlete; Volleyball.

\section{ABSTRAK}

Penelitian dilatarbelakangi oleh kurangnya motivasi berprestasi di bidang akademik atlet bola voli di kabupaten majalengka. Salah satu upaya dalam meningkatkan motivasi berprestasi dalam bidang akademik yaitu menggunakan bimbingan belajar. Salah satu wahana untuk meningkatkan kualitas sumber daya manusia tersebut dapat dilakukan melalui bidang keolahragaan. Permainan bolavoli merupakan salah satu cabang olahraga yang sudah sangat memasyarakat. Tujuan melakukan olahraga bolavoli sangat beragam, dari yang sekedar untuk hiburan atau rekreasi, olahraga kesehatan, olahraga pendidikan sampai dengan yang bertujuan untuk mencapai prestasi yang maksimal. Penelitian ini bertujuan untuk (1)Mengetahui profil motivasi belajar atlet bola voli sebelum dan sesudah diberikan bimbingan belajar, (2)Menghasilkan program bimbingan belajar untuk meningkatkan motivasi belajar atlet bola voli, (3)Memperoleh data empiric tentang efektivitas program bimbingan belajar untuk meningkatkan motivasi belajar atlet. Untuk menghasilkan bimbingan belajar yang efektif ditempuh dengan studi pendahuluan, pengembangan instrument, uji kelayakan instrumen, pengembangan bimbingan belajar, uji kelayakan bimbingan belajar dan uji coba bimbingan belajar Pendekatan penelitian ini menggunakan pendekatan kuantitatif dengan metode kuasi eksperimen dan desainnya adalah pretest-postest control grup desain terhadap atlet bola voli O2SN di kabupaten Majalengka. Pengumpulan data menggunakan alat ukur berupa instrumen motivasi berprestasi. Hasil penelitian menunjukkan secara empirik, perlakuan berupa bimbingan belajar teruji tidak efektif dalam meningkatkan motivasi berprestasi atlet bola voli. Diharapkan mengetahui tingkat motivasi berprestasi atlet bola voli diawal perkuliahan, agar dapat merencanakan program yang harus dilakukan Motivasi berprestasi

Kata Kunci: Berisi dua sampai lima kata/frasa dengan tanda baca titik koma pemisah 


\section{Pendahuluan}

Kemajuan prestasi olahraga tidak akan lepas dari pengaruh kemajuan pengetahuan dan teknologi. Permainan bolavoli merupakan salah satu cabang olahraga yang sudah sangat memasyarakat. Pelaku atau partisipan olahraga bola voli di masyarakat sangat beraneka ragam, terdiri dari banyak kalangan dari anak-anak, pemuda hingga orang tua baik dari kalangan ekonomi rendah, sedang maupun tinggi. Tujuan melakukan olahraga bolavoli sangat beragam, dari yang sekedar untuk hiburan atau rekreasi, olahraga kesehatan, olahraga pendidikan sampai dengan yang bertujuan untuk mencapai prestasi yang maksimal.

Malangnya Nasib Mantan Atlet Indonesia, para.13 dan para.14) bahwa "Kuncinya adalah pendidikan. Pada saat mereka menjadi atlet nasional itu pendidikannya diperhatikan". Dalam proses mengenyam dan mendapatkan suatu pendidikan formal, seseorang tak akan lepas dari suatu motivasi untuk menjalani pendidikan tersebut. Motivasi tersebut biasanya disebut dengan motivasi belajar. Berdasarkan fenomena dari beberapa artikel dan penelitian di lapangan tentang atlet yang dibaca oleh peneliti, kebanyakan penelitian meneliti tentang prestasi atlet dalam bidang olahraga. Namun belum ada yang meneliti tentang seberapa besar motivasi yang dimiliki atlet dalam kegiatan belajar pada jenjang pendidikan formal, sedangkan pendidikan formal juga memiliki peran yang sangat penting bagi masa depan atlet. Oleh karena itu, atlet juga harus memiliki motivasi berprestasi yang tinggi dalam pendidikan formal agar dapat memperoleh pengetahuan dan keterampilan pada pendidikan formal secara maksimal.

Pencapaian standar prestasi digunakan oleh atlet untuk menilai kegiatan yang pernah

dilakukan. Atlet yang menginginkan prestasi yang baik akan menilai kegiatan yang dilakukannya sesuai dengan kriteria yang telah ditetapkan. Berdasarkan penjelasan di atas, maka peneliti akan melaksanakan penelitian bimbingan belajar untuk meningkatkan motivasi berprestasi atlet o2sn bola voli di kabupaten majalengka.

\section{Metode Penelitian}

Penelitian ini bertujuan untuk menghasilkan program bimbingan belajar yang efektif untuk meningkatkan motivasi berprestasi atlet, sehingga metode penelitian yang digunakan adalah penelitian eksperimen. Metode penelitian eksperimen yang digunakan adalah kuasi eksperimen, metode ini dilakukan dengan memberikan yang dalam pelaksanaannya menggunakan penugasan acak (random assignment). Desain yang digunakan dalam penelitian ini adalah Pretest-Posttest Control Group Design. Bahwa dalam desain ini terdapat dua kelompok yang dipilih secara random, kemudian diberi pretest untuk mengetahui keadaan awal kedua kelompok tersebut.

Keefektifan ditinjau dari hasil perbandingan post test kelompok eksperimen dan kontrol. Bila nilai O2 secara signifikan lebih tinggi dari O4, maka treatment yang dilaksanakan efektif. Hal tersebut harus dipastikan bahwa pengujian nilai O1 dan O3 adalah seimbang (Sugiyono, $2010 \mathrm{hlm}$ 416-417).

Teknik yang dipilih untuk pengumpulan data dalam penelitian ini adalah dengan menggunakan angket atau kuesioner. Jenis angket yang digunakan dalam penelitian ini adalah jenis angket tertutup. Dalam mengumpulkan data, angket yang disebarkan kepada responden 
berbentuk pernyataan-pernyataan mengenai motivasi berprestasi yang terdiri dari aspekmempunyai tanggung jawab pribadi, menetapkan nilai yang akan dicapai, berusaha bekerja kreatif, berusaha mencapai cita-cita, melakukan antisipasi, dan melakukan kegiatan sebaikbaiknya.Angket yang disebarkan berisi 70 item pernyataan,baik dalam tahap penelitian tes awal (pretest) maupun tes akhir (posttest).

\section{Hasil dan Pembahasan}

Pembahasan hasil penelitian ini meliputi. 1) profil motivasi berprestasi atlet bola voli, dan 2) gambaran efektifitas bimbingan belajar untuk meningkatkan motivasi berprestasi.

1. Profil Motivasi Berprestasi atlet bola voli

Secara umum hasil penelitian menunjukkan profil motivasi berprestasi atlet bola voli o2sn di kabupaten Majalengka berada pada kategori sedang (94\%) yang artinya motivasi berprestasi yang ditandai dengan pencapaian aspek pengetahuan, sikap dan keterampilan yang cukup, yang meliputi 4-6 indikator (Pemahaman tentang hambatan yang akan dihadapi, Perkirakan akan hasil yang akan dicapai, Analisis akan manfaat, Mengelola suasana perasan, Menerima suasana perasaan, Menghayati suasana, keinginan untuk dapat umpan balik atas kegiatan yang dilakukan, melakukan sesuatu untuk mencapai kesuksesan, tujuan yang realistis, resiko akan hambatan, menghasilkan stategi baru untuk penyelesaian tugas, dengan indikator tertinggi mewakali setiap aspek yaitu Analisis akan manfaat dari pencapaian tujuan tertentu, melakukan sesuatu untuk mencapai kesuksesan.

2. Gambaran Efektifitas Bimbingan belajar untuk meningkatkan motivasi berprestasi atlet bola voli

Berdasarkan uji efektifitas bahwa hasilnya bimbingan belajar efektif untuk meningkatan motivasi berprestasi atlet bola voli, yang artinya terdapat perubahan perilaku sebelum dan sesudah diberikan perlakuan berupa bimbingan belajar, perubahan perilaku itu ditandai dengan peningkatan aspek pengetahuan atlet bola voli dengan indikatornya meliputihlm. Pemahaman tentang hambatan yang akan dihadapi, Perkirakan akan hasil yang akan dicapai, Analisis akan manfaat, Mengelola suasana perasan, Menerima suasana perasaan, Menghayati suasana, keinginan untuk dapat umpan balik atas kegiatan yang dilakukan, melakukan sesuatu untuk mencapai kesuksesan, tujuan yang realistis, resiko akan hambatan, menghasilkan stategi baru untuk penyelesaian tugas, dengan indikator tertinggi mewakali setiap aspek yaitu Analisis akan manfaat dari pencapaian tujuan tertentu., melakukan sesuatu untuk mencapai kesuksesan.

Hasil penelitian menunjukkan bahwa motivasi berprestasi atlet bola voli berada pada kategori sedang. Hal ini disebabkan karena beberapa faktor yaitu pada penelitian ini, sampel penelitian merupakan atlet bola voli semester 1 yang tergolong baru dan masih berada pada tahap orientasi, sehingga banyak diantaranya belum terlalu fokus dalam kegiatan belajar. Sesuai dengan rekomendasi yang diberikan oleh guru pembimbing dimana terdapat berbagai kesulitan yang dialami peserta didik dalam pencapaian prestasi, hal tersebut terlihat dari keseharian peserta didik di sekolah. Pihak sekolah belum memiliki program bimbingan khususnya program bimbingan belajar yang dikhususkan untuk meningkatkan motivasi berprestasi atlet bola voli. 
Proses pelaksanaan program bimbingan belajar untuk meningkatkan motivasi berprestasi atlet bola voli dilakukan selama 11 (sebelas) sesi. Masing-masing sesi atau pertemuan dijelaskan sebagai berikut.

1. Pelaksanaan layanan sesi ke-1 yakni kemampuan awalku.

Kegiatan pada sesi ini dilaksanakan pada tanggal 19 Juni 2019. Pada sesi ini untuk mengungkap profil motivasi berprestasi atlet bola voli menggunakan instrumen motivasi berprestasi. Tujuan pada sesi ini yaitu atlet bola voli mampu mengetahui tingkat motivasi berprestasinya dengan mengisi instrumen pengungkap motivasi berprestasi untuk kemudian diketahui tingkat kebutuhan program bimbingan belajar dari profil motivasi berprestasi atlet bola voli yang terungkap.

2. Pelaksanaan layanan sesi ke-2 yakni orientasi layanan.

Kegiatan layanan bimbingan belajar sesi ke dua dilaksanakan pada tanggal 21 juni 2019. Sesi ke dua dilakukan dengan menggunakan strategi bimbingan klasikal. Metode yang digunakan pada pelaksanaan layanan sesi ke dua ini adalah diskusi dan tanya jawab. Tujuan pada sesi ini yaitu atlet bola voli mengetahui tingkat motivasi berprestasi berdasarkan hasil pengolahan data instrumen motivasi berprestasi pada sesi tes awal, memahami tujuan dari layanan bimbingan belajar sebagai salah satu upaya yang dapat memfasilitasi mereka dalam meningkatkan motivasi berprestasinya, dan melakukan kontrak kegiatan dengan atlet bola voli untuk menyepakati waktu pelaksanaan kegiatan layanan bimbingan belajar. Setelah disampaikannya maksud dan tujuan dari kegiatan layanan bimbingan belajar, akhirnya disepakati waktu pelaksanaan layanan yakni setiap hari 2 hari sekali.

3. Pelaksanaan Layanan sesi ke 3 "Saya harus berprestasi?"

Kegiatan sesi ketiga berjudul "Saya harus berprestasi" yang dilaksanakan pada hari Senin tanggal 26 juni 2019. Sesi ke tiga dilakukan dengan menggunakan strategi bimbingan klasikal. Metode yang digunakan pada pelaksanaan layanan sesi ke tiga ini adalah menutar video dan diskusi. Tujuan sesi ke tiga ini adalah membantu atlet bola voli mengetahui hambatan apa saya yang akan dihadapi atlet bola voli untuk mengejar cita citanya. Dalam sesi ini konselor memutarkan video atau menceritakan tentang bagaimana seorang remaja keturunan Afrika Amerika yang berprestasi dibidang akademik dan basket. Bertujuan agar atlet bola voli mempelajari mengenai bagaimana orang yang berprestasi.

4. Pelaksanaan layanan sesi ke 4 yang berjudul "Mengatur waktu, pake strategi dong".

Kegiatan layanan bimbingan belajar sesi ke empat dilaksanakan pada tanggal 28 juni 2019. Sesi ke empat dilakukan dengan menggunakan strategi bimbingan klasikal. Metode yang digunakan pada pelaksanaan layanan sesi ke empat ini adalah diskusi dan tanya jawab. Tujuan dari pelaksanaan sesi ini adalah agar atlet bola voli Atlet bola voli memahami apa yang akan dilakukan untuk mencapai kesuksesan. Pada kegiatan layanan bimbingan belajar sesi ke empat ini, konselor membuka sesi dengan salam dan berdoa, mengecek kehadiran atlet bola voli, menjelaskan tujuan dan deskripsi kegiatan. Kemudian melanjutkan kegiatan dengan melakukan ice breaking, lalu berdiskusi mengenai materi layanan dan melakukan tanya jawab. Setelah atlet bola voli berdiskusi dan melakukan tanya jawab mengenai materi, konselor merefleksikan kegiatan yang telah dilaksanakan dan menyimpulkan materi yang telah dibahas.

5. Pelaksanaan layanan sesi ke 5 yang berjudul "saya bisa santai". 
Pelaksanaan sesi ke lima ini dilakukan pada tanggal 3 juli 2019. Sesi ke lima dilakukan dengan menggunakan strategi bimbingan klasikal.. Tujuan dari pelaksanaan sesi ini adalah agar atlet bola voli mampu menerima suasana perasaan ketika menghadapi ujian, dan atlet bola voli mampu berkonsentrasi. Kemudian konselor membuka sesi dengan salam dan berdoa, mengecek kehadiran atlet bola voli, menjelaskan tujuan dan deskripsi kegiatan. Lalu konselor membagi kedalam 6 kelompok berjumlah 5 orang, kemudian membuat kegiatan permainan kelompok berupa mewarnai gambar secara bergantian dengan kelompoknya, tanpa diperbolehkan berbicara. 6. Pelaksanaan layanan sesi ke-6 yang berjudul "Bermimpilah untuk Sukses dan wujudkan".

Pelaksanaan sesi ke enam ini dilakukan pada hari sabtu tanggal 5 juli 2019 . Sesi ini dilakukan dengan strategi bimbingan kelompok, di mana seluruh atlet bola voli diminta untuk membuat sebuah kelompok yang terdiri dari 4-5 orang. Pelaksanaan sesi ke tujuh ini dilakukan pada tanggal 10 juli 2019 . Sesi ini dilakukan dengan strategi bimbingan kelompok, di mana seluruh atlet bola voli diminta untuk membuat sebuah kelompok. Tujuan pada sesi ini yaitu agar atlet bola voli mampu mencapai tujuan yang realistis dengan sebaik mungkin agar mencapai prestasi. Selain itu, diharapkan atlet bola voli siap untuk belajar dengan sungguh-sungguh sehingga mampu mengatasi kegagalan yang mungkin terjadi.

7. Pelaksanaan layanan sesi-7 yang berjudul "Saya adalah pelajar...".

Pelaksanaan sesi ke tujuh ini dilakukan pada tanggal 12 juli 2019. Sesi ini dilakukan dengan strategi bimbingan kelompok, di mana seluruh atlet bola voli diminta untuk membuat sebuah kelompok. Metode yang digunakan pada pelaksanaan layanan sesi ke tujuh ini adalah simulasi. Tujuan Atlet bola voli mempelajari lebih lanjut tentang apa yang akan dicapainya, atlet bola voli memperkirakan hasil yang akan dicapainya selama di bangku perkuliahan

8. Pelaksanaan layanan sesi-8 yang berjudul "ketika saya sukses".

Sesi ke delapan ini dilaksanakan pada tanggal 17 juli 2019. Sesi ini dilakukan dengan strategi bimbingan kelompok, di mana seluruh atlet bola voli diminta untuk membuat sebuah kelompok yang terdiri dari 4-5 orang. Metode yang digunakan pada pelaksanaan layanan sesi ke delapan ini adalah bermain peran. Tujuan pada sesi ini yaitu menumbuhkan pemahaman dan kemampuan atlet bola voli terhadap kebutuhan akan umpan balik dan bagaimana meresponnya

9. Pelaksanaan layanan sesi-9 yang berjudul "cerdik seperti kancil".

Sesi ke sembilan ini dilaksanakan pada hari Rabu tanggal 12 januari 2017. Sesi ke sembilan dilakukan dengan menggunakan strategi bimbingan klasikal. Metode yang digunakan pada pelaksanaan layanan sesi ke sembilan ini adalah studi kasus. Tujuan pada sesi ini yaitu Atlet bola voli memahami bagaimana menghasilkan stategi baru untuk menyelesaikan tugas untuk meningkatkan motivasi berprestasi.

10. Pelaksanaan layanan sesi-10 yang berjudul "Inisiatifkah Anda?".

Sesi ke sepuluh ini dilaksanakan pada Hari jumat tanggal 13 januari 2017. Sesi ke sepuluh ini dilakukan dengan menggunakan strategi bimbingan kelompok. Metode yang digunakan pada pelaksanaan layanan sesi ke sepuluh ini adalah diskusi dan tanya jawab. Tujuan pada sesi ini yaitu atlet bola voli atlet bola voli menganalis apa tujuan yang akan dicapainya, dan dicari manfaat nya seperti apa. Konselor menutup kegiatan layanan dan memberitahukan kepada para atlet bola voli, bahwa layanan bimbingan belajar akan ditutup dengan pelaksanaan kegiatan tes akhir (posttest) pada pertemuan berikutnya. 
11. Pelaksanaan layanan sesi-11 Tes Kemampuan Akhirku

Kegiatan tes kemampuan akhirku ini dilakukan dengan menggunakan alat/ instrumen pengungkap motivasi berprestasi setelah diberikannya perlakuan. Tujuan pada sesi ini yaitu atlet bola voli mengetahui perubahan tingkat motivasi berprestasinya dan diketahui efektivitas program bimbingan belajar yang telah dilaksanakan.

\section{Kesimpulan}

Penelitian ini menghasilkan program bimbingan belajar untuk meningkatkan motivasi berprestasi atlet bola voli, yang dikembangkan secara teoretis dan empiris. Untuk menghasilkan bimbingan belajar yang efektif ditempuh dengan studi pendahuluan, pengembangan instrument, uji kelayakan instrumen, pengembangan bimbingan belajar, uji kelayakan bimbingan belajar dan uji coba bimbingan belajar. hasil penelitian menunjukkan bahwa bimbingan belajar efektif untuk meningkatkan motivasi berpretasi atlet bola voli.

\section{Daftar Pustaka}

Ahmadi Nuril. (2007). Panduan olahraga Bola Voli. Solo: Pustaka Utama.

Atkinson, J. (1982). Motivation and Achievement. Washington, D.C: V.H. Winston and Son. Atkinson

Arikunto, S. (2010). Prosedur Penelitian: Suatu Pendekatan Praktik (Edisi Revisi V). Jakarta: PT. Rineka Cipta.

Layanan Bimbingan dan Konseling dalam Jalur Pendidikan Formal. Bandung: Asosiasi Bimbingan dan Konseling Indonesia.

Depdiknas. (2008). Rambu-rambu Penyelenggaraan Pendidikan Profesional Konselor.

Djaali, H. (2007). Psikologi Pendidikan. Jakarta: Bumi Aksara.

Djumhur, I., dan Surya, M. (1975). Bimbingan dan Penyuluhan di Sekolah (Guidance \& Counseling). Bandung: CV Ilmu.

Erdiyanti, Yucky Putri (2013). Profil motivasi berprestasi dan implikasinya terhadap bimbingan konseling. SKRIPSI.

Erdiyanti, Yucky Putri (2017) . Program bimbingan akademik untuk meningkatkan motivasi berprstasi. TESIS 
Hamalik, Oemar, (2004), Proses Belajar Mengajar, Jakarta Bumi Aksara

Koeswara, E. (1995). Teori Motivasi dan Penelitiannya. Bandung: Angkasa. Moekijat. 2001. Dasar dasar Motivasi. Bandung: Pioner Jaya

Munandar, U. (1999). Kreativitas dan Keterbakatan: StrategiMewujudkan Protensi Kreatif dan Bakat. Jakarta: Gramedia Pustaka Utama.

Nurikhsan, J. (2006). Bimbingan dan Konseling dalam Berbagai Latar Kehidupan. Bandung: Refika Aditama.

Raymond J.W. \& Judith H.j., (2004). Motivasi Belajar. Jakarta: Cerdas Pustaka. Robbins, 2001, "Perilaku Organisasi“, Jilid 1 Edisi 8, PT Prenhalindo, Jakarta.

Robinson B. (1993). Bola Voli (bimbingan, petunjuk \& teknik Bermain). Jakarta: Dahara Prize

Rosyadi, M.A. (2010). Quantum Learning Sebagai Metode Bimbingan Belajar untuk Meningkatkan Motivasi Belajar Siswa. Skripsi. FIP UPI. Bandung: tidak diterbitkan.

Mempengaruhi Keberhasilan Studi , Ed. Kartini Kartono. Jakarta: CV Rajawali

Sobur, A. (2003). Psikologi Umum dalam Lintasan Sejarah. Bandung: Pustaka Setia.

Suhadi \& Sujarwo .(2010). Volleyball for all. Yogyakarta: Fakultas Ilmu Keolahragaan UNY. Sukadji. (2001). Motivasi dalam Masyarakat. Jakarta :Gramedia.

Sukardi, Dewa ketut. 2000. Bimbingan dan Konseling di Sekolah. Jakarta: Rineka Cipta

Sukardi, Dewa ketut. (2002). Pengantar Pelaksanaan Program Bimbingan dan Konseling di sekolah. Jakarta: Rineka Cipta.

Sukardi, Dewa ketut. (2008). Metodologi Penelitian Pendidikan: Kompetensi dan Praktiknya. Jakarta: Bumi Aksara.

Sukmadinata, N.S. (2003). Landasan Psikologis Proses Pendidikan. Bandung: Rosdakarya.

Sukmadinata, N.S. . (2012). Metode Penelitian Pendidikan. Bandung: PT. Remaja Rosdakarya.

Suryabrata, Sumadi. (1981). Psikologi Belajar. Jakarta: Depdikbud 
Supraba, Dellawaty, (2012). Hubungan Motivasi Berprestasi dengan Prokrastinasi Akademik Atlet bola voli Tingkat Akhir Fakultas Pendidikan Psikologi Universitas Negeri Malang. Skripsi, Jurusan Psikologi, Fakultas Pendidikan Psikologi, Universitas Negeri Malang

Suyanti. (1994). Pengaruh Motivasi Berprestasi terhadap Prestasi Belajar Siswa di SMP Negeri 1 Balerejo.

Syah, M. (2003). Psikologi Belajar. Jakarta: PT. Raja Grafindo Persada.

Undang-undang SISDIKNAS (Sistem Pendidikan Nasional) 2003 (UU RI No. 20 TH. 2003). Jakarta: Sinar Grafika.

Uno, H.B. (2006). Teori Motivasi dan Pengukurannya. Jakarta: Bumi Aksara.

Yusuf, S. (2009). Program Bimbingan dan Konseling di Sekolah. Bandung: Rizqi Press.

Yusuf, S. (2010). Psikologi Perkembangan Anak \& Remaja. Bandung: PT Remaja Roda 